\title{
BM] Global Health It is time to revise the international Good Clinical Practices guidelines: recommendations from non-commercial North-South collaborative trials
}

\author{
Raffaella Ravinetto, ${ }^{1,2}$ Halidou Tinto, ${ }^{3}$ Ermias Diro, ${ }^{4}$ Joseph Okebe, ${ }^{5}$ \\ Yodi Mahendradhata, ${ }^{6}$ Suman Rijal, ${ }^{7}$ Eduardo Gotuzzo, ${ }^{8}$ Pascal Lutumba, ${ }^{9}$ \\ Alain Nahum, ${ }^{10}$ Katelijne De Nys, ${ }^{11}$ Minne Casteels, ${ }^{2}$ Marleen Boelaert ${ }^{1}$
}

To cite: Ravinetto $\mathrm{R}$, Tinto $\mathrm{H}$, Diro $\mathrm{E}$, et al. It is time to revise the international Good Clinical Practices guidelines: recommendations from noncommercial North-South collaborative trials. BMJ Global Health 2016;1: e000122. doi:10.1136/ bmjgh-2016-000122

Received 7 July 2016 Revised 23 September 2016 Accepted 26 September 2016

CrossMark

For numbered affiliations see end of article.

Correspondence to Dr Raffaella Ravinetto; rravinetto@itg.be

\section{ABSTRACT}

The Good Clinical Practices (GCP) codes of the WHO and the International Conference of Harmonization set international standards for clinical research. But critics argue that they were written without consideration for the challenges faced in low and middle income countries (LMICs). Based on our field experience in LMICs, we developed a non-exhaustive set of recommendations for the improvement of GCP. These cover 3 domains: ethical, legal and operational, and 8 specific issues: the double ethical review of 'externally sponsored' trials; the informed consent procedure in minors and in illiterate people; post-trial access to newly-developed products for the trial communities; the role of communities as key research actors; the definition of sponsor; and the guidance for contractual agreements, laboratory quality management systems, and quality assurance of investigational medicinal products. Issues not covered in our analysis include among others biobanking, standard of care, and study designs. The international GCP codes de facto guide national legislators and funding agencies, so the current shortcomings may weaken the regulatory oversight of international research. In addition, activities neglected by GCP are less likely to be implemented or funded. If GCP are meant to serve the interests of global society, a comprehensive revision is needed. The revised guidelines should be strongly rooted in ethics, sensitive to different sociocultural perspectives, and allow consideration for trial-specific and context-specific challenges. This can be only achieved if all stakeholders, including researchers, sponsors, regulators, ethical reviewers and patients' representatives from LMICs, as well as non-commercial researchers and sponsors from affluent countries, are transparently involved in the revision process. We hope that our limited analysis would foster advocacy for a broad and inclusive revision of the international GCP codes, to make them at the same time 'global', 'context centred' and 'patient centred'.

\section{INTRODUCTION}

Despite the advancements of medical science, huge disparities remain between

\section{Key questions}

What is already known about this topic?

- The Good Clinical Practice (GCP) codes of the WHO and the International Conference of Harmonisation were issued in 1995-1996.

- They are meant to provide public assurance that the rights, safety and well-being of trials' participants are protected, and that data generated are credible.

- It has been suggested that they lack consideration for the challenges of clinical research in low and middle income countries.

What are the new findings?

- We looked at issues that are frequently mentioned as a source of uncertainties or challenges in clinical research in low and middle income countries.

- We developed a non-exhaustive set of field-rooted recommendations for the improvement of the international GCP codes.

- Our recommendations cover ethical, legal and operational issues, ranging from the ethical review of 'externally sponsored' trials to the quality assurance of investigational medicinal products.

\section{Recommendations for policy}

- The international GCP codes should be revised to take into account the current challenges in international clinical research.

- The international GCP codes should be strongly rooted in ethics, sensitive to different sociocultural perspectives, and allow consideration for trial-specific and context-specific challenges.

- Not only regulators, but all the key stakeholders in clinical research, should be fairly and transparently involved in the revision process.

high income countries (HICs) and low and middle income countries (LMICs) in access to adequate care. Clinical research is no exception to this divide. On the one hand, 
pharmaceutical research and development (R\&D) has historically neglected the diseases that mainly or exclusively hit LMICs. ${ }^{1}$ On the other hand, trial participants in LMICs may be more exposed to poor research practices and exploitation, in particular because of social vulnerability: poverty and lack of access to healthcare may limit voluntariness, and trial participation may become a strategic choice to secure otherwise unavailable health and non-health resources. ${ }^{24}$ Concerns about possible exploitation have been raised in sub-Saharan Africa, ${ }^{5} 6$ India, ${ }^{7}$ Latin America, ${ }^{8}$ and South-East Asia. ${ }^{10} 11$

The last two decades have also seen the 'globalisation of clinical trials', that is, trials are increasingly delocalised to non-US and non-Western European settings. ${ }^{12-15}$ This is due to different reasons, including external valid$i t$, that is, the need to test new interventions in a variety of epidemiological settings and populations; convenience, that is, the opportunity of lower costs, easier ethical/regulatory review and easier availability of participants; ${ }^{12} 16$ and global health, that is, the need to address the specific health needs of local populations. 'Globalisation' concerns both commercial trials, generally sponsored by a pharmaceutical company and aimed at the development of new medicines/medical products, and non-commercial trials, sponsored by non-commercial actors (eg, academia, non-governmental organisations, international organisations, etc). The latter are essential for R\&D of medical products of no direct commercial interest, for assessing the effectiveness/feasibility of health interventions in specific contexts/groups and for providing independent comparative evaluations. ${ }^{17}$

All clinical trials, whether in HICs or LMICs, and whether commercial or non-commercial, must comply with adequate ethical and methodological standards. The Good Clinical Practices (GCP) codes of the WHO and of the International Conference of Harmonisation (ICH) set such international standards. Their goal is to provide public assurance that the rights, safety and well-being of participants are protected, and that data generated are credible. ${ }^{18}{ }^{19}$ But critics argue that they were written without considering the relevant scientific literature,${ }^{20}$ and that they lack consideration for the challenges faced in LMICs. ${ }^{21} 22$ The latter is not surprising, since the international GCP were published in 1995-1996, when trials were mainly conducted in Western contexts by commercial sponsors. The ICH-GCP code is currently under revision, ${ }^{23}$ but the revision's limited scope has been questioned by leading academic groups (http://moretrials.net/).

\section{A PRACTICE-BASED SET OF RECOMIMENDATIONS}

On the basis of our experience in non-commercial, North-South collaborative trials, we would like to contribute to the debate on whether the international GCP codes adequately address today's challenges in globalised clinical research. We developed a non-exhaustive set of recommendations that cover three domains: ethical, legal and operational. Even if we prevalently focused on sub-Saharan Africa, a region which been seriously underrepresented in decision-making platforms in clinical research, ${ }^{24}$ we selected eight specific issues that appeared to be frequently mentioned as a source of uncertainties or challenges across the different research groups represented by the authors of this paper (coming from sub-Saharan Africa, Asia, Latin America and Europe).

\section{Ethical challenges}

Double ethical review

Trials undertaken in a host country but sponsored, financed, and conducted by an external organisation, are called externally sponsored. ${ }^{16}$ The Council for International Organizations of Medical Sciences (CIOMS) Guidelines and the Nuffield Council on Bioethics recommend that they are subject to the 'double ethical review', that is, ethical review carried out in the study country and in the sponsor's country. ${ }^{16} 25$ This mechanism is also suggested by independent research groups ${ }^{26}$ but it is generally not legally enforced, and the international GCP codes are silent on it.

We evaluated the double ethical review in a multicountry malaria trial, ${ }^{27}$ and in an emergency Ebola trial. ${ }^{28}$ Given the high number of involved countries or committees, it practically resulted in a 'multiple' ethical review. Procedurally, it was complex, due to a multiplicity of requirements. Its impact on the trials' timelines was variable. In the 'routine' malaria trial, it took up to 9 months to secure all approvals, which caused delays in the trial's milestones. In the Ebola trial, conducted under the tight schedule of a public health emergency, the ethical reviews were fast, with no impact on the study's milestones. Content wise, the double ethical review was beneficial: the complementarity of perspectives improved the quality of the protocols and the protection of patients and communities. But the efficiency of the process would have been enhanced by joint reviews, or at least by direct dialogue between the different committees. ${ }^{29}{ }^{30}$ Direct dialogue would also have allowed exchanges across the committees, mutual learning and managing conflicting opinions or inconsistent recommendations (for instance, in the Ebola-Tx trial, it was requested at the same time to shorten the informed consent form, and to add more elements to it).

We suggest that, in absence of a pre-existing harmonised regulatory framework between the host and the sponsor country, the international GCP code incorporates the notion of double ethical review for externally sponsored trials, and recommends measures to make it more efficient, for example, by promoting direct dialogue between the involved committees.

\section{Minors' consent}

The international GCP code requires that when minors are enrolled in clinical trials, informed consent is given by the parents or a 'legally acceptable representative', 
acting in the minor's best interest. But the concept of 'legal representative' is not consistent with the practice in many LMICs, where guardians are not formally nominated by a tribunal. For instance, Vischer $e t a l^{11}$ mention the difficulty of finding legally acceptable representatives for children as a major challenge when implementing GCP in African settings. In countries like the Democratic Republic of Congo, ${ }^{2}$ Burkina Faso and Benin, children are informally entrusted to relatives or community members. The management of the child's routine clinical care is delegated to these caregivers, but one cannot assume that the terms of delegation encompass decisions concerning participation in trials, particularly when the 'informal caregiver' is appointed on a temporary basis.

To skip this challenge, researchers might decide not to enrol children cared by an informal caregiver, but this would unfairly exclude from research the most vulnerable ones, in addition to creating a selection bias. Alternatively, they could ignore the question, by accepting the self-declared guardian without further investigation. This is likely to occur in practice, and brings the risk of obtaining the consent from a person not entitled to give it or not acting in the child's best interest. Local ethics committees, having access to comprehensive information on research carried out in their region, are in the best position to develop locally-tailored good practices. For instance, in Zimbabwe, the caregivers of HIV orphans were not legally entitled to decide on the participation in the AntiRetroviral Research fOr Watoto (ARROW) trial. The ethics committee thus waived the legal guardianship requirement, allowing caregivers to provide consent, provided that they signed an ad hoc affidavit. ${ }^{32}$

These challenges cannot be ignored. We suggest that the international GCP codes accept and regulate the notion of 'ethically and socioculturally acceptable representative', beside the one of 'legal representative'. The way the representative is designated and the conditions under which he/she is entitled to act should be described in the protocol, be compliant with ethical principles and local laws and regulations, and should get an explicit ethical approval. This mechanism should not lower children's protection. On the contrary, it could strengthen it, by structuring and controlling informal mechanisms that are already in place.

\section{Illiteracy}

Illiteracy may exacerbate vulnerability, so adequate measures are needed to ensure protection of illiterate people in medical research. The international GCP codes require that an 'impartial witness' confirms that their consent is given in full autonomy, with no undue influence or coercion. However, finding impartial witnesses for illiterates may be a major challenge in some African settings. ${ }^{31}$ In addition, local interpersonal dynamics may impair the function of the witness, especially in contexts with high illiteracy rates, where patients without a literate relative/friend are assigned a witness previously unknown to them. This may be perceived as a breach of privacy, or as an imposition of the views of the witness, rather than an opportunity to foster dialogue and improve understanding. ${ }^{2}$

These observations are limited to Central Africa and should be confirmed in comparable settings. However, they strongly suggest that the mere presence of an independent witness is not per se sufficient to ensure participants protection. The international GCP codes could acknowledge these complexities and underline the need of context-tailored measures to ensure that the "witnessed consent' process achieves its objective of protecting, rather than being the mere implementation of a formal requirement.

\section{Post-trial access}

Research ethics guidelines concur that research may only be conducted in a given population if it is 'pertinent', and if there is a reasonable likelihood that the research results will be available to that population. ${ }^{16}$ In practice, this means that innovative medicines should be made available to those in need in the countries where the trials were conducted. If this does not happen, there are legitimate concerns that trials were delocalised for convenience reasons. ${ }^{12}$ But few legislations have binding clauses for post-trial access to research results to the study communities.

Available evidence shows that trials' globalisation is not accompanied by strategies for making new medicines available and affordable in the trial countries. A limited analysis of commercial trials for haematological malignancies showed that about $30 \%$ of phase 3 trials involved sites in middle income countries (MICs) that are usually unable to sustain the high costs of the marketed medicines. ${ }^{33}$ Others showed that clinical trials conducted in India, South Africa and Latin America, often did not result in market authorisations in the study countries. ${ }^{34} 35$

According to Dauda and Dierickx ${ }^{36}$ benefit-sharing should be formulated into a legal framework for international research, to ensure a better protection of poor trials' communities. We would complete this call by advocating that the principles of 'benefit-sharing' and 'post-trial access to research results to host communities' are incorporated in the international GCP codes.

\section{The community}

There are major differences across countries, and across communities within a country, in terms of culture, population, economic indicators, education, infrastructure, quality of healthcare, etc. ${ }^{30}$ In addition, the perspectives on research held by the communities often differ from those held by investigators, sponsors and ethics committees. For instance, social vulnerability may create a 'push' to trial participation, ${ }^{4}$ while concerns surrounding the meaning and reasons for collecting biological samples may create a reluctance to enrol. ${ }^{37} 38$ Our experience strongly suggests that researchers should 
gain an upfront, in-depth and multifaceted understanding of the perspectives of each community, for example, of how research is perceived and how local features and beliefs may influence comprehension and voluntariness, ${ }^{39}$ and that interdisciplinary qualitative research may help to build a genuine partnership between clinical researchers and communities.

Community engagement is increasingly promoted in health research, particularly in the field of HIV-AIDS. ${ }^{40}$ However, there is no universally accepted definition of 'community engagement': the concept itself, and the way in which it is best implemented in practice, remains not sufficiently studied. ${ }^{41}$ In addition, there is no national or international regulation on community engagement, ${ }^{41}$ and the international GCP codes do not list the community among the actors in clinical research.

For pushing to consistently achieve true engagement with trials' communities across different groups and disciplines, and not only in participatory research, we suggest that international GCP guidelines formally include the community (and/or patients associations) among the key-actors in clinical research.

\section{Legal challenges}

Non-commercial sponsors

The GCP definition of a sponsor, that is, 'an individual, company, institution or organisation which takes responsibility for the initiation, management and/or financing of a clinical trial', does not capture the situation of most non-commercial trials. These are 'externally-funded', thus the legal responsibility (sponsor) and the funding source (external funding agency) are de facto split. The ambiguity of the GCP definition exposes inexperienced sponsors to the risk of underestimating the scope and extent of their own responsibility. ${ }^{42}$ Furthermore, the dependence on external funding often results in budget constraints and/or poor flexibility, ${ }^{43}$ and the competition for external funds is so great that most non-commercial sponsors are not in the position to question the conditions set by funders. ${ }^{42}$ The sponsor's definition of new European Regulation on Clinical Trials, ${ }^{44}$ which uses the wording 'setting up the financing of' a trial instead of 'financing' it, better represents the reality of externally funded research.

The international GCP codes would better reflect today's reality of international research, if the distinction between commercial sponsors (in charge of 'initiation, management and financing') and non-commercial, externally-funded sponsors (in charge of 'initiation, management and securing the financing from third parties') was acknowledged.

\section{Contractual agreements}

Contractual negotiations may be a major challenge for non-commercial sponsors who often have limited contract management capacity. ${ }^{43}$ This seems particularly true for South-based sponsors. According to the Council in Health Research for Development (COHRED), 'recent snapshot surveys of research institutions in the African and Asian regions have revealed some significant gaps in the contracting and contract management capacity in these regions' ${ }^{45}$ The major challenges identified by COHRED include the negotiation on the overheads, the supply of investigational medicinal products (IMPs), the transfer and sharing of trials' data and samples, and the policy insurance contract.

Public guidance in these domains is either absent or quite vague, both in GCP and from national regulators. For instance, we lack guidelines on how to meaningfully negotiate data sharing and material transfer agreements. Similarly, there are few or no concrete guidelines for negotiating research policy insurance contracts, ${ }^{46}$ which may result in poor insurance arrangements, leading to insufficient protection for participants and to increased liability risks for the sponsors.

The international GCP codes could give helpful guidance for non-commercial research, by providing as annexes some guidance for key-research contracts. This could then be adapted at national level, especially in countries that lack detailed regulatory guidance.

\section{Operational challenges}

Laboratory quality management systems

Laboratories processing specimens from clinical trials require an appropriate set of good practices. The upgrade of local laboratories and the harmonisation of laboratory quality systems represent a major challenge in LMICs, especially in rural or remote areas. ${ }^{21} 46$ Unfortunately, the international GCP codes put little focus on laboratory requirements, and they do not refer to the Good Clinical Laboratory Practices (GCLP) code, first issued in 2003 in the UK and retaken in 2009 by the United Nations Development Program (UNDP)World Bank-WHO Special Programme for Research and Training in Tropical Diseases (TDR). ${ }^{47}$ The GCLP code provides a useful GCP-compliant framework for the analysis of biological samples from clinical trials.

The poor attention of GCP for trials' laboratories may be explained by the fact that commercial sponsors in HICs rely on accredited laboratories, already run under a structured quality system. Unfortunately, the neglect of GCP for trial's laboratories triggers poor awareness of their importance among non-commercial sponsors and funding agencies (which often ignore the GCLP code).

We propose that international GCP should include a dedicated section describing the qualifications, responsibilities and monitoring/supervision of trial laboratories, including a cross-reference to GCLP. ${ }^{47}$ This provision would put GCP in line with the priority needs of globalised clinical research, and would help to ensure the quality, integrity and traceability of laboratory-generated data in international clinical trials.

Investigational medicinal products

To ensure the quality of IMPs, the international GCP codes require compliance with locally applicable Good 
Manufacturing Practices (GMP). However, this is insufficient today, since a combination of globalisation of production and insufficient regulatory overview results in variable drug quality on the international market. ${ }^{48} 49$

Poor pharmaceutical quality may influence trials' results, and there is evidence that degraded, underdosed and non-bioequivalent medicines have or could have been used in clinical trials. ${ }^{50} 51$ These challenges were ignored by GCP in 1995-1996, but it is quite surprising that a more stringent reference to drug quality is not considered in the ongoing revision of the ICH GCP, since the lack of regulatory supervision on global pharmaceutical supply allowed poor-quality medicines to reach ICH countries, ${ }^{52}$ and at least in one case a falsified medicine could have been used as a comparator in a US trial. $^{53}$

If poor-quality medicines were used in clinical trials, they would harm patients, lead to erroneous results, and inappropriately inform public health policy. We support the call of Newton et a $\bar{l}^{\tilde{0}}$ that the international GCP codes should include more detailed and documented statements on the checking and reporting of the quality of drugs and medical devices in clinical research, and should require independent chemical analysis results for IMPs that are not approved by a stringent regulatory authority.

\section{CONCLUSION}

Our recommendations are not exhaustive. Unexplored issues include among others the ownership of biological samples, biobanking, standard of care, assent in minors, monitoring of safety and study designs. Also the field of applicability of GCP deserve more reflection: the GCP codes are primarily meant for trials with IMPs, but their adaptation to other biomedical studies (eg, diagnostic research, cluster randomised trials) is very relevant for non-commercial research in LMICs. The majority of our observations come from sub-Saharan Africa; we believe that it is important to give voice to researchers from this region who are generally under-represented in decisionmaking platforms in clinical research. ${ }^{24}$

Despite these limitations, our experience suggests that GCP currently gives inadequate attention to many challenges faced in LMICs. The international GCP codes $d e$ facto guide national legislators and funding agencies, so these shortcomings may weaken the regulatory oversight of international research, sometimes even diverting energies and resources from the most relevant priorities. In addition, those activities that are not sufficiently addressed in GCP are less likely to be implemented or funded.

A partial revision of the ICH-GCP Guidelines is ongoing, to modernise them and to 'facilitate broad and consistent international implementation of new methodologies' ${ }^{23}$ But if GCP is meant to serve the interests of global society, a more comprehensive revision is needed, to redesign procedures with a larger scope. The revised guidelines should be strongly rooted in ethics, sensitive to different sociocultural perspectives, and allow consideration for trial-specific and context-specific challenges. This can be achieved if all stakeholders, including researchers, sponsors, regulators, ethical reviewers from LMICs, as well as non-commercial researchers/sponsors and patients' representatives from all settings, are fairly and transparently involved in the revision process. This would help to overcome the communication gap between the field, academia and regulators, which has caused an unfortunate divide between the GCP codes and the concrete field challenges. Since every regulatory framework is the product of a particular historic context, a reasonable revision plan should also be put in place.

We hope that our limited set of recommendations would foster advocacy for a broader and inclusive revision of the international GCP codes, to make them at the same time 'global', 'context centred' and 'patient centred'.

\section{Author affiliations}

${ }^{1}$ Public Health Department, Institute Tropical Medicine, Antwerp, Belgium ${ }^{2}$ Department of Pharmaceutical and Pharmacological Sciences, KU Leuven, Leuven, Belgium

${ }^{3}$ Clinical Research Unit Nanoro, Nanoro, Burkina Faso

${ }^{4}$ Department of Internal Medicine, College of Medicine and Health Sciences, University of Gondar, Gondar, Ethiopia

${ }^{5}$ Medical Research Council Unit, The Gambia, Fajara, Gambia

${ }^{6}$ Faculty of Medicine, Center for Tropical Medicine, Universitas Gadjah Mada, Yogyakarta, Indonesia

${ }^{7}$ B.P. Koirala Institute of Health Science, Dharan, Nepal

${ }^{8}$ Department of Medicine, Alexander von Humboldt Institute of Tropical Medicine and Infectious Diseases, Lima, Peru

${ }^{9}$ University of Kinshasa, Kinshasa, Democratic Republic of Congo

${ }^{10}$ Centre des Recherches Entomologiques de Cotonou, Cotonou, Benin

${ }^{11}$ Clinical Trial Center, Leuven University Hospital, KU Leuven, Leuven, Belgium

\section{Handling editor Seye Abimbola}

Twitter Follow Raffaella Ravinetto at @RRavinetto

Contributors This paper is based on 9-year research experience of the Clinical Trials Unit of the Institute of Tropical Medicine (Belgium) and of the partners in the Switching the Poles Clinical Research Network. HT, ED, JO, YM, SR, EG, PL and AN are all members of the Network. The recommendations described in this article have been earlier described in a doctoral research, carried out by RR at KU Leuven (Belgium) under the supervision on MC, MB and KDN. The manuscript is available at https://lirias. kuleuven.be/handle/123456789/517274. A shortened version of the thesis was sent to the ICH Secretariat on 30th January 2016, signed by RR, MB, $\mathrm{MC}, \mathrm{KDN}, \mathrm{HT}, \mathrm{ED}, \mathrm{JO}, \mathrm{YM}, \mathrm{SR}, \mathrm{EG}, \mathrm{PL}$ and AN. RR wrote the draft version of this article, which was revised and approved by MB, MC, KDN, HT, ED, JO, YM, SR, EG, PL and AN. RR is the guarantor of this article.

Funding The Switching the Poles Clinical Research Network is funded as part of a programme for institutional capacity strengthening funded by the Belgian Development Cooperation. The Clinical Trials Unit of the Institute of Tropical Medicine (Antwerp, Belgium) is funded by the Department of Economy, Sciences and Innovation of the Flemish Government.

Disclaimer The funders have no role in the writing or approval of this paper.

Competing interests RR is a co-signatory of the MORE TRIALS open letter to the European Medicines Agency concerning the revision of the ICH Good Clinical Practices Guidelines (MORE TRIALS. To do more trials better. Accessed on 14th June 2016 at http://moretrials.net/). 
Provenance and peer review Not commissioned; externally peer reviewed.

Data sharing statement No additional data are available.

Open Access This is an Open Access article distributed in accordance with the Creative Commons Attribution Non Commercial (CC BY-NC 4.0) license, which permits others to distribute, remix, adapt, build upon this work noncommercially, and license their derivative works on different terms, provided the original work is properly cited and the use is non-commercial. See: http:// creativecommons.org/licenses/by-nc/4.0/

\section{REFERENCES}

1. Pedrique $B$, Strub-Wourgaft N, Some $\mathrm{C}$, et al. The drug and vaccine landscape for neglected diseases (2000-11): a systematic assessment. Lancet Glob Health 2013;1:e371-9.

2. Kalabuanga $M$, Ravinetto $R$, Maketa $V$, et al. The challenges of research informed consent in socio-economically vulnerable populations: a viewpoint from the Democratic Republic of Congo. Dev World Bioeth 2015;16:64-9.

3. Paré Toe L, Ravinetto RM, Diericks SI, et al. Could the decision of trial participation precede the informed consent process? Evidence from Burkina Faso. PLoS ONE 2013;8:e80800.

4. Ravinetto R, Afolabi MO, Okebe J, et al. Participation in medical research as a resource-seeking strategy in socio-economically vulnerable communities: call for research and action. Trop Med Int Health 2015;20:63-6.

5. Angell $\mathrm{M}$. The ethics of clinical research in the Third World. $N$ Engl J Med 1997;337:847-9.

6. Lenzer J. Pfizer settles with victims of Nigerian drug trial. BMJ 2011;343:d5268.

7. Yee A. Regulation failing to keep up with India's trials boom. Lancet 2012;379:397-8.

8. Aultman JM. Abuses and apologies: irresponsible conduct of human subjects research in Latin America. J Law Med Ethics 2013;41:353-68.

9. McCarthy M. US foundation, university, and drug company are sued for alleged role in Guatemala study. BMJ 2015;350:h1859.

10. van Teijlingen ER, Simkhada PP. Ethical approval in developing countries is not optional. J Med Ethics 2012;38:428-30.

11. Page-Shafer K, Saphonn V, Sun LP, et al. HIV prevention research in a resource-limited setting: the experience of planning a trial in Cambodia. Lancet 2005;366:1499-503.

12. Glickman SW, McHutchinson JG, Peterson ED, et al. Ethical and scientific implications of the globalization of clinical research. New Engl J Med 2009;360:816-23.

13. Lang T, Siribaddana S. Clinical trials have gone global: is this a good thing? PLoS Med 2012;9:e1001228.

14. Rehnquist J. The globalization of Clinical Trials: a growing challenge in protecting human subjects. Department of Health and Human Services, Office of Inspector General, September 2001. OEI-01-0000190. http://oig.hhs.gov/oei/reports/oei-01-00-00190.pdf (accessed 14 Sep 2015)

15. The European Group on Ethics in Science and New Technologies to the European Commission. Opinion on the Ethical Aspects of Clinical research in Developing Countries. Opinion $\mathrm{N}^{\circ}$ 17, 4th February 2003. http://europa.eu/rapid/ press-release_IP-03-193_en.htm?locale=en (accessed 14 Sep 2015).

16. Council for International Organizations of Medical Sciences (CIOMS) in collaboration with the World Health Organization (WHO) International ethical guidelines for biomedical research involving human subjects. Geneva, Switzerland, 2002. http://www.cioms.ch/ publications/layout guide2002.pdf (accessed 14 Jun 2016).

17. Federal Kenniscentrum voor de Gezondheidszorg. Health Services Research. Publicly funded practice-oriented clinical trials. KCE Report 246c, 2015. https://kce.fgov.be/publication/report/ publicly-funded-practice-oriented-clinical-trials (accessed $14 \mathrm{Sep}$ 2015).

18. World Health Organization (WHO). Guidelines for Good Clinical Practices for trials on pharmaceutical products. WHO Technical Report Series No. 850, Annex 3. Geneva, Switzerland, 1995. http:// apps.who.int/medicinedocs/pdf/whozip13e/whozip13e.pdf (accessed 14 Jun 2016)

19. International Conference of Harmonization (ICH). $\mathrm{ICH}$ Tripartite Guideline for Good Clinical Practices E6 (R1), 10th June 1996. http://www.ich.org/fileadmin/Public_Web_Site/ICH_Products/ Guidelines/Efficacy/E6/E6_R1_Guideline.pdf (accessed 14 Jun 2016).
20. Grimes DA, Hubacher D, Nanda K, et al. The Good Clinical Practice guideline: a bronze standard for clinical research. Lancet 2005;366:172-425.

21. White NJ. Editorial: clinical trials in tropical diseases: a politically incorrect view. Trop Med Int Health 2006;1:1483-4.

22. Lang T, Cheah PY, White NJ. Clinical research: time for sensible global guidelines. Lancet 2011;77:1553-5.

23. International Conference of Harmonization (ICH) of Technical Requirements for Registration of Pharmaceuticals for Human Use. ICH Harmonized Guidelines. Integrated Addendum to ICH E6(R1): Guideline for Good Clinical Practices. http://www.ich.org/fileadmin/ Public_Web_Site/ICH_Products/Guidelines/Efficacy/E6/E6_R2 Addendum Step2.pdf (accessed 14 Jun 2016).

24. Ravinetto R, Becker SL, Sacko M, et al. Governance and Standards in International Clinical Research: the role of transnational consortia. Am J Bioethics 2016;16:59-61.

25. Nuffield Council on Bioethics. The ethics of research related to healthcare in developing countries. London, UK: Nuffield Council on Bioethics, 2002. http://nuffieldbioethics.org/wp-content/uploads/2014/ 07/Ethics-of-research-related-to-healthcare-in-developing-countries-I. pdf (accessed 17 Sep 2015)

26. Bompart F, Hirsch F, Bertoye PH, et al., et les participants de la table ronde n. 1 de Giens XXIII. Bonnes Pratiques Cliniques dans les pays en développement: recommandations en termes d'application. Thérapie 2008;63:77-82.

27. Ravinetto R, Buvé A, Halidou T, et al. Double ethical review of North-South collaborative clinical research: hidden paternalism or real partnership? Trop Med Int Health 2011;16:527-30.

28. De Crop M, Delamou A, van Griensven J, et al. Multiple ethical review in North-South collaborative research: the experience of the Ebola-Tx trial in Guinea. Indian J Med Ethics 2016;1:76-82.

29. World Health Organization (WHO). Background document on potential Ebola therapies and vaccines. http://www.who.int/csr/ disease/ebola/ebola-new-interventions-02-sep-2014.pdf (accessed 19 Sep 2015).

30. Coleman $\mathrm{CH}$, Ardiot $\mathrm{C}$, Blesson $\mathrm{S}$, et al. Improving the quality of host country ethical oversight of international research: the use of a collaborative pre-review for a study of fexinidazole for human African trypanosomiasis. Dev World Bioeth 2015;15:241-7.

31. Vischer N, Pfeiffer C, Joller A, et al. The GCP guideline and its interpretation-perceptions of clinical trial teams in sub-Saharan Africa. Trop Med Int Health 2016;21:1040-8.

32. Bwakura-Dangarembizi M, Musesengwa R, Nathoo KJ et al. Ethical and legal constraints to children's participation in research in Zimbabwe: experiences from the multicenter pediatric HIV ARROW trial. BMC Med Ethics 2012;13:17.

33. Ravinetto R, Guenzi PD, Massat P, et al. Globalisation of clinical trials and ethics of benefit sharing. Lancet Hematology 2014;1: e54-6.

34. Limaye D, Langer JM, Rühling T, et al. A critical appraisal of clinical trials conducted and subsequent drug approvals in India and South Africa. BMJ Open 2015;5:e007304.

35. Homedes N, Ugalde A. Availability and affordability of new medicines in Latin American countries where pivotal clinical trials were conducted. Bull World Health Organ 2015;93:674-83.

36. Dauda B, Dierickx K. Benefit sharing: an exploration on the contextual discourse of a changing concept. BMC Med Ethics 2013;14:36.

37. Peeters Grietens K, Muela Ribera J, Erhart A, et al. Doctors and vampires in sub-Saharan Africa: ethical challenges in clinical trial research. Am J Trop Med Hyg 2014;91:213-15.

38. Bannister-Tyrrel M, Gryseels C, Delamou A, et al. Blood as medicine: social meanings of blood and the success of Ebola trials. Lancet 2015;385:420.

39. World Health Organization-Special Programme for Research and Training in Tropical Diseases (WHO-TDR). Ethical challenges in study design and informed consent for health research in resource-poor settings. Special topics No. 5. 2007 TDR/SDR/SEB/ ST/07.1. http://apps. who.int/iris/bitstream/10665/43622/1/ 9789241563383 eng.pdf (accessed 19 Sep 2015).

40. Joint United Nations Programme on HIV/AIDS (UNAIDS). Good participatory practice Guidelines for biomedical HIV prevention trials. Geneva, Switzerland: Joint United Nations Programme on HIV/AIDS (UNAIDS), 2011.

41. Participants in the Community Engagement and Consent Workshop, Kilifi, Kenya, March 2011. Consent and Community Engagement in diverse research contexts. J Empir Res Hum Res Ethics 2013:8:1-18.

42. Ravinetto R, De Nys K, Boelaert M, et al. Sponsorship in non-commercial clinical trials: definitions, challenges and the role of Good Clinical Practices guidelines. BMC Int Health Human Rights 2015;15:34. 
43. Idoko OT, Kochhar S, Agbenvega TE, et al. Impact, challenges, and future projections of vaccine trials in Africa. Am J Trop Med Hyg 2013;88:414-19.

44. Directive 2001/20/EC of the European Parliament and of the Council of 4 April 2001 on the approximation of the laws, regulations and administrative provisions of the Member States relating to the implementation of good clinical practice in the conduct of clinical trials on medicinal products for human use. http://ec.europa.eu/ health/files/eudralex/vol-1/dir_2001_20/dir_2001_20_en.pdf (accessed 19 Sep 2015).

45. Marais $\mathrm{D}$, Toohey $\mathrm{J}$, Edwards $\mathrm{D}$, et al. Where there is no lawyer: guidance for fairer contract negotiation in collaborative research partnerships. Geneva \& Pietermaritzburg: Council in Health Research for Development (COHRED), 2013. http://www.cohred.org/ wp-content/uploads/2012/04/Fair-Research-Contracting-GuidanceBooklet-e-version.pdf (accessed 19 Sep 2015).

46. Ravinetto RM, Talisuna A, De Crop M, et al. Challenges of non-commercial multicentre North-South collaborative clinical trials. Trop Med Int Health 2013;18:237-4.

47. World Health Organization (WHO). Good Clinical Laboratory Practices. WHO on behalf of the Special Programme for Research and Training in Tropical Diseases (TDR). 2009. http:// www.who.int/tdr/publications/documents/gclp-web.pdf (accessed 14 Jun 2016)

48. Caudron JM, Ford N, Henkens M, et al. Substandard medicines in resource-poor settings: a problem that can no longer be ignored. Trop Med Int Health 2008;13:1062-72.

49. Newton PN, Amin AA, Bird C, et al. The primacy of public health considerations in defining poor quality medicines. PLoS Med 2011;8: e1001139.

50. Newton PN, Schellenberg D, Ashley EA, et al. The quality assurance of medicines used in clinical trials: proposal for adapting guidelines. BMJ 2015;350:h602.

51. Belew S, Getachew M, Suleman S, et al. Assessment of efficacy and quality of two Albendazole brands commonly used against soil-transmitted helminth infections in school children in Jimma town, Ethiopia. PLoS Negl Trop Dis 2015;9:e0004057.

52. Tanne $\mathrm{JH}$. Four deaths and 350 adverse events lead to US recall of heparin. BMJ 2008;336:412-13.

53. Medicines and Healthcare Products Regulatory Agency (MHRA) MHRA annual statistics 2010-2011. Enforcement. Medicines. Operation Singapore. http://www.mhra.gov.uk/home/groups/comms-ic/ documents/websiteresources/con123239.pdf (accessed $18 \mathrm{Sep}$ 2015). 